\title{
Energy consumption of emulsification processes in small-sized mix apparatuses
}

\author{
(C) Nikolay S. Shulaev, ${ }^{+}$Tatiana V. Shulaeva, ${ }^{*}$ and Sergey V. Laponov \\ The Branch of Federal State Budget Educational Institution of Higher Vocational Education \\ "Ufa State Petroleum Technical University" in Sterlitamak. Oktyabrya St., 2. Sterlitamak, 453118. \\ Republic of Bashkortostan. Russia.Phone: +7 (9625) 27-45-73. E-mail: Laponows92@mail.ru
}

*Supervising author; ${ }^{+}$Corresponding author

Keywords: rotary, reactor, mixer, disk, emulsification.

\begin{abstract}
There is given in this thesis a general method of calculation of power consumption for emulgation in systems liquid-liquid in small-size mixing devices (rotor-pulsation apparatuses and rotor-disc mixers). This mixing devices, have shown a high efficiency at processing of liquid-liquid systems and are wide using chemical processes. The base of calculation method is an energy ratio to describe of developed turbulent motion, pulsation intensity of which is enough for create of dispersed particles of given size and concentration, which provide a necessary surface of phases contact. It is shown, that in determination of energy consumption it is need to take in account energy dissipation processes, due to viscous friction forces, which have a significant influence at high gradients of turbulent motion. There is obtained a ratio, which connects an angular velocity of rotor rotation of mixing device and a characterized size of dispersed phase particles.There is given an experimental dependencies of consumed power of rotor-disc mixers on rotor rotations number of mixing device and characterized sizes of dispersed particles for systems water-diesel fuel. It was determined, that are decreasing of dispersed particles sizes and in increasing of volumetric flow of processing mixture a value of consumed power increases, and it is related with by increase of energy consumption for creating of interphase surface. It was determined, that a power, consumed by rotor-disc mixer, for emulsion making with averaged dispersion size of particles at range $5-25 \mathrm{mkm}$, increases by increase of rotation numbers $\sim n^{0.37}$. Comparison of theoretical equations and experimental data have shown adequacy of supposed calculation method of energy consumption.
\end{abstract}

\section{References}

[1] N.S. Shulayev, E.A. Nikolayev, S.P. Ivanov. Low-volume rotor-disc mixers. Moscow: Chemistry. 2009. 186p. (russian)

[1] S.V. Laponov, N.S. Shulaev, S.P. Ivanov, and I.G. Ibragimov. Carbonization of a soda solution in rotary disc reactors. Butlerov Communications. 2018. Vol.53. No.3. P.118-123. DOI: 10.37952/ROI-jbc-02/18-53-3-118

[2] S.V. Laponov, N.S. Shulayev, I.G. Ibragimov, S.P. Ivanov. Features of emulsification in rotor-disc mixers. Oil and gas industry. 2016. Vol.14. No.4. P.126-129. (russian)

[3] L.N. Braginsky, V.I. Begachev, V.M. Barabash. Mixing in liquid medias Physical bases and engineer methods of calculation. Leningrad: Chemistry. 1984. 336p. (russian)

[4] L.D. Landau, E.M. Lifshitz. Hydrodynamics. Moscow: Science. 1988. 736p. (russian) 